\title{
The Role of Intuition in Entrepreneurship and Business Venturing Decisions
}

\begin{abstract}
Entrepreneurial intuition is the affectively-charged recognition and evaluation of a business venturing opportunity arising as a result of involuntary, rapid, non-conscious, associative processing. This article integrates theories of dual-processing and models of business venturing (opportunity recognition, evaluation and exploitation) in a 'default-intervention model of entrepreneurial intuition' which links the defaults of intuitive expertise, cognitive style, somatic state and the affect heuristic with System 2 interventions and the contingencies of the decision environment. Six research propositions are offered with suggestions for how they can be tested. The theoretical and practical implications of entrepreneurial intuition are discussed in terms of the unfolding of a research agenda relating to this important but undertheorized and under-researched construct in work and organizational psychology.
\end{abstract}

Keywords: decision-making; dual-process; dual-system; entrepreneurship; intuition 


\section{INTRODUCTION}

Entrepreneurship is the 'engine room' of the economy (Mitchell, 2005), and successful entrepreneurs often attribute their accomplishments to the 'knack' of being able to identify and judge business opportunities 'intuitively'. The popular business press is replete with examples of entrepreneurs crediting their successes to 'instinct' (Mehta, 2013), 'hunch' (Barrow, 2009), or 'gut feel' (Welch \& Byrne, 2001). But should the claims of such 'intuitive entrepreneurs' be taken with a pinch of salt? On the other hand how much do behavioural scientists know about intuition's role in the recognition, evaluation, and exploitation of business opportunities? This article addresses these questions by: developing a model of intuitive processing in business venturing decisions; offering a number of research propositions and empirical directions; discussing the theoretical and practical significance of an improved understanding of 'entrepreneurial intuition'. This research is part of an on-going endeavour to "put the person back into entrepreneurship research" (Rauch \& Frese, 2007: 353), further explaining the differences between entrepreneurs and non-entrepreneurs and between successful and unsuccessful business venturing decisions (e.g. Utsch \& Rauch, 2000), and connecting entrepreneurship research with wider debates and developments in the behavioural and brain sciences (e.g. Reimann \& Bechara, 2010).

\section{BACKGROUND}

The proposed theoretical model integrates the construct of intuition with the process of entrepreneurship. Intuitions are involuntary "affectively charged judgments that arise through rapid non-conscious and holistic associations" (Dane \& Pratt, 2007: 40). They are an outcome of variety of cognitive and affective processes (e.g. recognition, pattern matching, somatic marking) operating within and between a number of processing systems and subsystems (e.g. System 1 and System 2, Type 1 and Type 2) and brain regions (e.g. ventromedial pre-frontal cortex, amygdala) (Bechara \& Damasio, 2005; Epstein, Pacini, 
Denes-Raj, \& Heier, 1996; Evans \& Stanovich, 2013a; Lieberman, 2007). Intuitive judgements are domain-specific manifestations of expertise (Hogarth, 2001, 2010; Klein, 2003; Sadler-Smith \& Shefy, 2004; Salas, Rosen, \& DiazGranados, 2010) evoked and executed under conditions of uncertainty, dynamism, and time pressure (Burke \& Miller, 1999). Indeed, some researchers refer explicitly to intuition as 'problem-solving intuition' (Dane \& Pratt, 2009) or 'expert intuition' (Gore \& Sadler-Smith, 2011). Nobel laureate Herbert Simon (1916-2001) captured succinctly the essence of experts' intuitions when he described them as "analyses frozen into habit and the capacity for rapid response through recognition" (Simon, 1987: 63). The capability to exercise 'intuitive expertise' (Kahneman \& Klein, 2009) is built-up over several years' learning, practice, reflection, and feedback (Benner \& Tanner, 1987; Dreyfus \& Dreyfus, 1986; Ericsson, Prietula \& Cokely, 2007; Klein, 1998, 2003; Salas et al., 2010) in environments which are conducive to the development of accurate complex domain-relevant schemas (CDRSs, Dane \& Pratt, 2007). Such environments have "stable relationships between objectively identifiable cues and subsequent events or between cues and the outcomes of possible actions" (Kahneman \& Klein, 2009: 524). For this reason such environments are sometimes referred to as 'benign' or 'high-validity' environments (Hogarth, 2001, 2010; Kahneman \& Klein, 2009).

Entrepreneurship is defined as the "discovery, evaluation, and exploitation of future goods and services" (Eckhardt \& Shane, 2003: 336). The process of entrepreneurship consists of three stages punctuated by decision-making episodes at crucial junctures: (1) opportunity recognition (Baron, 2006): entrepreneurs require sufficient prior knowledge in order to be able to combine existing ideas in novel and creative ways in discovering new opportunities; (2) opportunity evaluation (Keh, Foo, \& Lim, 2002): entrepreneurs require the cognitive and affective resources to be able to appraise the viability and potential for value creation of a discovered opportunity; (3) opportunity exploitation (Shane \& Venkataraman, 
2000): entrepreneurs must have the motivational, cognitive, and social abilities, skills, and resources to be able to engage in the exploitation of viable new discoveries. An implication is that an effective entrepreneur ought to be able to not only perceive (i.e. recognise) those opportunities which have potential commercial value but also discriminate between (i.e. evaluate) those opportunities which have a potential value that is worth pursuing and those which do not.

Intuition's role in this process is twofold: (1) spontaneous recognition of salient cues in the environment and their re-combination in novel and creative ways; (2) evaluation of the recognised opportunity such that intuitive affective responses ('gut feelings', 'hunches', 'vibes') signal 'approach' or 'avoid' behaviours. Intuition is more relevant in the opportunity recognition and opportunity evaluation stages of business venturing because these stages rely on pattern and prototype recognition (Baron \& Ensley, 2006), venture-situational knowledge (Smith, Mitchell, \& Mitchell, 2009), heuristic processing (Vaghely \& Julien, 2010), use of effectual and non-predictive logic (Read, Dew, Sarasvathy, Song, \& Wiltbank, 2009), active scanning, divergent thinking and 'connecting dots' (Tang, Kacmar, \& Busenitz, 2012), and use of 'affect as information' (Foo, Uy, \& Baron, 2009). In the opportunity exploitation stage entrepreneurs are more likely to rely on deliberative analytical cognition (Schenkel, Matthews, \& Ford, 2009) and contextual factors such as social networks and deployment of relational capital (De Carolis, Litzky, \& Eddleston, 2009), resource possession and building venture networks (Smith, et al, 2009), and familiarity with and ability to use a 'language of organizing' (Autio, George, \& Alexy, 2011).

Entrepreneurial intuition is defined as the affectively-charged recognition and evaluation of a business venturing opportunity arising as a result of involuntary, rapid, nonconscious, associative processing (cf. Dane \& Pratt, 2007). Positioning and defining intuition in this way, i.e. at the nexus of cognition and affect, is important for the 
entrepreneurship literature because researchers previously have focused either on entrepreneurial cognition (e.g. Gregoire, Barr \& Shepherd, 2010) or on entrepreneurial affect (e.g. Baron, 2008) rather than considering the possibility of their being conceptually conjoined. The concept of 'entrepreneurial intuition' helps to explain the joint roles of intuitive cognition and intuitive affect in the business venturing process.

\section{THEORISING ENTREPRENEURIAL INTUITION}

More than a quarter of a century ago Bird (1988) argued that 'entrepreneurial intentionality' is driven by two complementary processes:

"Rational, analytic, and cause and-effect-oriented processes structure [entrepreneurial] intention and action. These psychological processes underlie formal business plans, opportunity analysis, resource acquisition, goal setting, and most observable goal-directed behaviour" [whereas] "intuitive, holistic, and contextual thinking frames and structures an entrepreneur's intention and action. Inspired by vision, hunch, an expanded view of untapped resources, and a feeling of the potential of the enterprise" (Bird, 1988: 443, original emphases)

Bird did not frame this novel, compelling and powerful two-process idea into a psychologically coherent argument because at the time the necessary theoretical resources were not well-developed or known widely outside psychology (e.g. Schneider \& Shiffrin, 1977; Shiffrin \& Schneider, 1977). The fact that dual-processing accounts now "abound in cognitive and social psychology" (Evans, 2008: 256) and are used both in psychology (Evans, 2003, 2008; Kahneman, 2011) and management (Hodgkinson, Sadler-Smith, Burke, Claxton \& Sparrow, 2009) puts organizational psychologists and management researchers in the fortunate position to be able to re-frame Bird's prescient insights in terms of a generic dual-system/dual-process theory.

A foundational assumption of this article as far as understanding the important question of "how do entrepreneurs think and make strategic decisions" (Mitchell, Busenitz, Lant, McDougall, Morse, \& Smith, 2004: 608) is concerned is that a distinction exists 
between intuitive and rational analytic information processing. This fundamental "dichotomy in human thinking" (Allinson \& Hayes, 1996: 123) is referred to variously as automatic/controlled (Schneider \& Shiffrin, 1977), associative/rule-based (Sloman, 1996; Smith \& DeCoster, 2000), experiential/rational (Epstein, 1994; Epstein, Pacini, Denes-Raj, \& Heier, 1996; Pacini \& Epstein, 1999), implicit/explicit (Reber, 1993), intuitive/analytic (Hammond, 1996), reflexive/reflective (Lieberman, 2007), etc. and more generically as System 1 and System 2 processing (Evans, 2008; Kahneman, 2011; Stanovich \& West, 2000) or Type 1 and Type 2 (Evans \& Stanovich, 2013a) processing (see Evans \& Stanovich 2013a for a discussion of process-versus-system denominations).

The attributes of these two information processing systems may be summarized briefly as follows: (1) the intuitive system is automatic, low effort, experiential, heuristic, implicit, intuitive, holistic, unconscious, domain specific, slow-learning/fast-operating (for this reason it has been referred as the reflexive system, or X-system, Lieberman, 2007), affective (Epstein et al., 1996), phylogenetically older ('old mind', Evans \& Stanovich, 2013a); (2) the analytical system is controlled, high effort, rational, systematic, explicit, analytic, conscious, domain general, and fast-learning/slow-operating (for this reason it has been referred to as the reflective system, or C-system, Lieberman, 2007), logical (Epstein et al., 1996), phylogenetically more recent ('new mind', Evans \& Stanovich, 2013a). Typical clusters of attributes associated with the two systems are summarized in Table 1. Readers are referred to Epstein (1994), Evans (2008), Lieberman (2007), and Stanovich and West (2000) for reviews. Stanovich and West (2000) enumerated no less than twelve distinct variants of the generic dual model but noted "clear family resemblances" (p.658) to the extent that irrespective of the differences they all "essentially posit two minds in one brain" (Evans 2003: 454). Dual-process theories are well-placed to illuminate the role of intuitive 
processing in entrepreneurs' business venturing decisions given the insights they offer into the joint roles of cognition and affect.

[TABLE 1 HERE]

Dual-process and dual-system theories are not without their critics (see: Keren \& Schul, 2009; Osman, 2004). Readers are referred to Evans and Stanovich for a detailed consideration of the debate (Evans \& Stanovich, 2013a\&b); suffice to say Evans and Stanovich conclude that although dual-process theory is an "evolving project" the evidence in its favour is "compelling" and a "very clear theoretical basis for the two-process distinction has now emerged" (2013a: 237). Notwithstanding the latter, a substantive issue highlighted by Evans and Stanovich (2013a), and one which is pertinent to our discussions, is the 'parallel-competitive' (e.g. Sloman, 1996) versus 'default-interventionist' (Evans, 2007) views that contend within dual-process accounts. The former assumes that "Type 1 and 2 processing proceed in parallel" (Evans \& Stanovich, 2013a: 227), whereas the latter assumes that "intuitive answers are prompted rapidly and with little effort when people are confronted by novel problems" (p.237) and that "subsequent reflective Type 2 processing may or may not intervene" on involuntary intuitions (p.227). Evans and Stanovich (2013a) argue convincingly in support of the default-interventionist position. There does not, as yet, appear to be any palpable or compelling theoretical or empirical basis to deviate from this view in respect of entrepreneurial intuition. However, the exact nature of the default mechanisms as they pertain to business venturing decisions is unclear. The default-intervention model of entrepreneurial intuition presented in this article seeks to specify theoretically the nature of these defaults.

Affect deserves particular consideration in developing any model of entrepreneurial decision making given the significance accorded to it by entrepreneurs themselves (Barrow, 
2009; Mehta, 2013; Welch \& Byrne, 2001) and by entrepreneurship researchers (Baron, 2006; Cardon, Foo, Shepherd \& Wiklund, 2012; Goss, 2005). It is especially relevant to models of intuitive decision making because affect is linked explicitly to the operations of System 1 in a number of dual-process theories. For example, Cognitive-Experiential SelfTheory (Epstein 1994) posits "two fundamentally different ways of knowing" referred to as the 'rational system' (corresponding to System 2) and the 'experiential system' (corresponding to System 1); the latter is "associated with feelings and experience", the former with "intellect" (Epstein, 1994: 710). The operation of the experiential system is:

"Preconscious, automatic, effortless, rapid, minimally demanding of cognitive capacity, intimately associated with affect, holistic, associative, and imagistic, and its outcome is experienced passively (we are seized by our emotions) and as self-evidently valid (experiencing is believing)" (Epstein, 2000: 671).

Relatedly, Lieberman and colleagues in distinguishing between the so-called reflective (C) and reflexive (X-) systems (Lieberman, 2007) argued that the X-system automatically constructs "affective aspects of the stream of consciousness" producing "habitual responses and impulses" that guide behaviour (Lieberman, Jarcho \& Satpute, 2004: 424). Affective responses in respect of intuition are often referred to metaphorically as 'gut feelings', 'hunches', or 'vibes' (Epstein et al., 1996) and manifest as “subtle changes in bodily systems" (Dunn et al., 2010: 1835). In this respect Damasio (2000) offers an important distinction between "primary emotions" (happiness, sadness, fear, anger, surprise, disgust) and "background emotions" which allow us to have 'background feelings' such as anticipation or dread (p.52). The ability to detect signals associated with more subtle changes in bodily systems (the "body landscape", Damasio, 2000: 281) is referred to as ‘interoception’ (Craig, 2002), and affords a biasing signal (positively- or negativelyvalenced) which may influence decision-making by spontaneously marking an image as 'good' or 'bad' (Dunn et al., 2010; Evans \& Stanovich, 2013a). Knowing when to trust or 
discount gut feelings has important implications for self-regulation and optimal decision making "at crucial junctures in life" (Dunn et al., 2010: 1834); business venturing decisions represent one such 'crucial juncture' for many entrepreneurs.

Applications of dual-processing theory to the study of affect and decision-making have moved beyond general assertions regarding 'emotion' (e.g. Cross \& Travaglione, 2003) having have refined the ways in which affect's role can be construed in understanding decision making under conditions of uncertainty and risk in field settings. Slovic, Finucane, Peters and MacGregor (2002) defined affect as follows: “the specific quality of 'goodness' or 'badness' (i) experienced as a feeling state (with or without consciousness) and (ii) demarcating a positive or negative quality [valence] of a stimulus" (p.329). As far as decision making behaviours are concerned, reliance on affect is "a quicker, easier, and more efficient [i.e. heuristic] way to navigate in a complex, uncertain, and sometimes dangerous world" in order to make choices regarding the risks and benefits associated with choices (Slovic et al., 2002: 330). Affect is a heuristic to the extent that it involuntarily presents a decision-maker with an 'easy-to-evaluate' attribute (see: Evans \& Stanovich, 2013a: 237). The significance of 'affect-as-information' in business venturing is supported both by entrepreneurs' own accounts (e.g. Branson, 2005) and research (Baron, 2008; Baron \& Ensley, 2006; Cardon, et al., 2012; Foo, 2011; Foo, Uy, \& Baron, 2009; Goss, 2005).

\section{DEFAULT-INTERVENTION MODEL OF ENTREPRENEURIAL INTUITION}

An important psychological question in entrepreneurship and business venturing research is: 'what is unique about entrepreneurs' cognitions that enables them to recognise, evaluate, and subsequently exploit potentially value-creating business opportunities?' (Ardichvili, Cardozo, \& Ray, 2003; Baron, 2004; Mitchell, et al., 2002; Zahra, Korri, \& Yu, 2005). A corollary of this question emanating from the dual-process view is 'what role does intuition [a System 1 process] play in entrepreneurs' cognitions?' These questions motivated the development of 
the model shown in Figure 1. Such a model is necessary because the application of theories of decision making to entrepreneurship (e.g. Busenitz \& Barney, 1997; Lyon, Lumpkin \& Dess, 2000; Shane \& Venkataraman, 2000) have emphasized the "operation of analytical processes" whilst overlooking the "key role" played by "more intuitive or emotional responses" (De Martino, Kumaran, Seymour, and Dolan, 2006: 684). In what follows: (1) the model's four main elements (intuitive expertise, cognitive style, somatic state, affect heuristic) are described and explained; (2) links between these constructs and the core entrepreneurial processes of opportunity recognition and opportunity evaluation are demonstrated; (3) consideration is given to the role of rational analytic (System 2) processing and environmental factors in the enactment of intuitive entrepreneurial judgments; (4) propositions are offered that link the main psychological constructs to the process of entrepreneurship with suggestions for how the hypothesized relationships might be tested.

\section{[FIGURE 1 HERE]}

\section{Intuitive Expertise}

The proposed effect of expertise on entrepreneurs' decision making behaviours and performance is based on two assumptions: (1) expertise is "reproducible superior performance in a particular domain [a coherent set of tasks and problems that are amenable to objective performance measurement]" (Lewandowsky, Little \& Kalish, 2007: 84); (2) a particular business opportunity pre-existed in an entrepreneur's environment as a latent pattern of cues prior to its discovery and remained "as potential" until its discovery (Baron \& Ward, 2004: 559). More generally, an individual's entrepreneurial orientation (EO) predisposes an individual to initiative, achievement risk-taking and has been shown to be linked to firm performance (Krauss, Frese, Friedrich \& Unger, 2005) hence 'being entrepreneurial' is also about being 'alert' (Kirzner, 2009). 
The ability to recognize the potential significance of complex assemblages of cues is a defining attribute of experts' performance (Dreyfus \& Dreyfus, 1986) based on domainspecific, complex, pattern-matching processes (Klein, 1998). The informational substrate of 'intuition-as-expertise' (Sadler-Smith \& Shefy, 2004) is slow-in-formation (taking typically ten years or more of learning and experience, see: Ericsson \& Ward, 2007) but fast-inoperation (see Lieberman, 2007). This contention is supported by two findings in entrepreneurship research: first, "successful entrepreneurs can be characterized by an expert mind-set" underpinned by a particular (i.e. deep) set of cognitive structures and beliefs (Krueger, 2007: 123); second, the mental models ('schemas' or 'prototypes') of experienced entrepreneurs are more complex than those of novices (Baron \& Ensley, 2006).

The cognitive foundations of intuitive expertise are complex domain-relevant schemas (CDRS, Dane \& Pratt, 2007), broadly equivalent to what Krueger (2007: 124) referred to as “deep cognitive structures”, Baron and Ensley (2006: 1331) as 'prototypes', and Blume and Covin (2011: 140) as "domain relevant knowledge". CDRSs develop as a result of implicit and explicit learning (Reber, 1993) in 'benign' (Evans \& Stanovich, 2013a), 'high validity' (Kahneman \& Klein, 2009), or 'kind' (i.e. conducive to learning) (Hogarth, 2010) environments over the longer-term (see Lieberman, 2007; Simon, 1987). The patterns, prototypes, and scripts of which CDRSs are comprised enable an expert to focus on key attributes of a task and identify problem-relevant cues (Baron \& Ensley, 2006; Baron \& Ward, 2004). Grégoire, Barr, and Shepherd (2010) observed that experienced entrepreneurs in encountering new information "considered the 'similarities' between this information and the context(s) [i.e. environment] where this information might be meaningful" (p.425). In the discovery of viable business venturing opportunities the possession of CDRSs is likely to yield repeat benefits over the longer term (Baron \& Ensley, 2006), thereby obviating the role of chance successes (first-time 'lucky hunches') in business venturing. The interactions 
between learning, experience, CDRSs, and the discovery of viable business ventures furtherbuild CDRSs, hence for a given domain:

Proposition 1: individuals who possess CDRSs will discover consistently more new business opportunities than individuals who do not possess CDRSs.

However, effective entrepreneurial intuition relies not only on an expert mind-set but also on the creative cognitions necessary to recognize gaps, identify novel possibilities, and 'connect the dots' to identify new business opportunities (Tang et al., 2012). Hence, an expert mindset is a necessary but insufficient condition for creative/divergent entrepreneurial cognitions. In this model it is proposed that individual differences in entrepreneurs' modes of information processing (i.e. thinking styles or cognitive styles) also play an important role in moderating the relationship between expertise and opportunity recognition (see Figure 1).

\section{Intuitive Cognitive Style}

Cognitive styles are individual differences in individuals' habitual approaches to representing, organizing, and processing information (Messick, 1984). Their efficacy in decision making and problem solving is contingent on the demands of the task (Miller, 1987) hence they manifest as "qualitatively different approaches to making decisions" (Salas et al., 2010: 949). Numerous dimensions of cognitive style have been identified and studied (Cools, Van den Broeck \& Bouckenooghe 2009; Kozhevnikov, 2007) and a number of them are conducive to the divergent thinking processes that enable idea generation. Hence, cognitive styles help to explain why certain individuals are able to recognize business venturing opportunities that are opaque to others. These processes are germane to the creative aspects of entrepreneurship such as 'need spotting', 'solution spotting' and 'mental invention' (Linton \& Walsh, 2008). Divergent thinking capability is a useful estimate of the capacity for creative thought and idea generation in general (Runco, 1991); in the business 
venturing context Dimov (2007) argued that it is the entrepreneur's style of thinking which is likely to determine the degree of convergence versus divergence in the identification of business venturing opportunities.

An intuitive cognitive style is characterized by unconventional and divergent thinking, cognitive fluidity, forming associations of prima facie unrelated components (Simonton, 1980), producing multiple answers, shifting perspectives, transforming the known and taking risks (Cropley, 2006), thinking globally, "distinguish[ing] the forest from the trees", and "judg[ing] which questions are important and which ones are not". (Sternberg, 2006: 89). Intuitive cognitive style is an antecedent of creativity (Raidl \& Lubart, 2001; Sinclair, 2010). Simonton described 'intuitives' as being able to make creative integrations requiring remote associations operating "below the threshold of cognition" on the basis of "physical, emotional [affective] and connotative relationships", appealing to "gut feelings" which may not have any apparently rational foundation (Simonton, 1980: 22, 26 and 49). It is proposed that an intuitive cognitive style augments intuitive expertise in the discovery of business venturing opportunities. Hence:

Proposition 2: Individuals who possess CDRSs and have an intuitive cognitive style will discover more new business opportunities than individuals who possess CDRSs and have an analytical cognitive style.

The intuition-analysis style dimension not only has a robust theoretical base in dual-process theory but also several valid and reliable measures exist for it (Akinci \& Sadler-Smith 2013; Coffield, Moseley, Hall, \& Ecclestone, 2004; Hodgkinson \& Sadler-Smith, 2003; Hodgkinson, Sadler-Smith, Sinclair \& Ashkanasy, 2009). Furthermore, the analysis-intuition dimension has been used already, albeit only limitedly, in entrepreneurial cognition research. For example, Allinson and Hayes (1996) found entrepreneurs to be more intuitive in their cognitive style than managers in general, and more similar in this regard to senior managers 
and executives. Brigham, De Castro, and Shepherd's (2007) study of person-organization fit in small high-tech firms found that intuitive owner managers were more comfortable than analytical owner managers in less-structured work environments (and vice versa). One of the problems with these studies is that any inferences that may be drawn are hindered by construct validation issues. More specifically, several entrepreneurship researchers (e.g. Allinson, Chell \& Hayes, 2000) have chosen to use instruments or score them in ways that are predicated upon untenable theoretical and empirical assumptions (e.g. Allinson and Hayes' (1996) Cognitive Style Index, CSI), or to use instruments with only tenuous links to any relevant or coherent body of psychological theory (e.g. Vance, Groves, Paik, and Kindler's (2007) Linear Non-Linear Thinking Styles Profile, LNTSP). Fortunately, several valid and reliable instruments that are entirely commensurable with dual-process theory are available to entrepreneurship researchers (see 'Future Directions' below).

The combined effects of intuitive expertise and intuitive cognitive style support the process of opportunity recognition, however such recognition is not enough; a business venturing opportunity must also be evaluated once it has been recognized. As noted intuitions are involuntary, rapid "affectively charged judgments" (Dane \& Pratt, 2007: 40), hence it is proposed that opportunities that are recognized intuitively are also evaluated spontaneously on the basis of the affective signals that comprise the entrepreneur's somatic state.

\section{Somatic State}

Entrepreneurial intuitions are expressed in conscious awareness as "the feeling of liking an entity or a feeling of risk" thereby providing a powerful means of intrapersonal communication (Betsch, 2008: 4). Intuitive affect manifests phenomenologically as 'gut feel' and serves as a criterion for selecting/approaching (positive valence) or rejecting/avoiding (negative valence) a particular business venturing option. Until comparatively recently the 
neural mechanisms involved in risk judgments were unclear, however developments in the brain sciences have shed light on the neuroanatomical systems implicated in risky and uncertain decision making.

In a series of foundational experiments generally referred to as the Iowa Gambling Task (IGT) studies, Bechara, Damasio and their colleagues employed neurophysiological measures (skin conductance responses, SCRs, also known as 'micro-sweating') of bodily (somatic) responses as participants made decisions of varying levels of risk during a simulated gambling task. In a clinical setting Damasio and colleagues compared the behaviour and physiological responses of normal patients (referred to as 'normals') with patients who had incurred damage to their brain's ventro-medial pre-frontal cortex (VMPC) and amygdala (regions associated with the infusion of affect into decision making). There were two key findings. Firstly, normals generated SCRs when they received financial reward or financial punishment as a result of their actions, and as they grew in experience in the task somatic responses approximating to what is commonly referred to as 'gut feel' (measured as minute changes in SCRs) were generated intuitively in anticipation of the conscious decision and were more strongly associated with riskier choices than safer choices. Secondly, patients with damage to the VMPC and amygdala failed to generate anticipatory SCRs.

The results of the IGT studies demonstrate the existence of somatic marker signals which contribute to a somatic state that guides decision making behaviours away from potentially disadvantageous and towards advantageous choices (Dunn et al., 2010). Bechara and Damasio (2005: 346) interpreted their findings as evidence that when the functionality of relevant brain regions (amygdala and VMPC) is impaired "the patient can no longer register how painful it feels when one loses money". Without the ability to generate the necessary affective signals VMPC-impaired individuals fail to avoid choices that lead to loss, and continue to make disadvantageous choices "until they go broke in a manner that is very 
similar to how they behave in real life" (ibid.). This is the basis of the Somatic Marker Hypothesis (SMH) (Bechara, Damasio, A., Damasio, H., \& Anderson, 1994; Bechara \& Damasio, 2005; Bechara, Tranel, Damasio, H. \& Damasio, A., 1996).

The SMH and the IGT program of research has provided neurological evidence that: (1) in effective decision making the emotional regions of the brain work in concert with higher cortical regions, especially under conditions of risky choice; (2) impairment of functioning of the relevant neural circuitry in the VMPC and amygdala may have serious and deleterious consequences for individuals' economic choices and behaviours. Moreover, consistent with the default-interventionist view (see Evans \& Stanovich, 2013a) it is likely that intuitive affect, in the form of a somatic marker, occurs rapidly, involuntarily and in advance of System 2 processing. On the basis of the foregoing discussions it is proposed that:

Proposition 3: Intuitive affective responses provide an autonomous approach/avoid signal which serves as a mechanism for narrowing down the range of options in business venturing environments characterized by risky choice.

\section{Affect Heuristic}

In pursuing further the role played by affect in intuitive judgment Slovic and colleagues proposed a decision heuristic in which affect influences the evaluation of perceived risks and benefits. In a series of laboratory studies Slovic and colleagues found that if a person's feelings about an object or activity are favourable (i.e. positively valenced) they judge the perceived risks of that activity to be low and the perceived benefits to be high; if a person's feelings towards an activity are unfavourable (i.e. negatively valenced) they judge the perceived risks of that activity to be high and its perceived benefits to be low (Finucane, Alkhami, Slovic, \& Johnson, 2000). The theory of the 'affect heuristic' proposes that these 
responses are an important part of a decision maker's somatic state, that people intuitively consult their affective feelings when making judgments and decisions, and people use such information to guide choice (Slovic, Finucane, Peters, \& MacGregor, 2004). Furthermore, the intuitive evaluation of a risky choice based on 'gut feeling' precedes intervention by rational analytic processes (see Evans \& Stanovich, 2013a). The affect heuristic has been shown to influence judgments in relation to the perceived risks and benefits in a variety of contexts including attitudes towards nuclear power, toxic hazards, and company stocks (Slovic, et al., 2004); it has yet to be used in business venturing research.

On the basis of somatic marking and the operation of the affect heuristic it is argued that the evaluation of a business venturing opportunity will be based on intuitively generated affective information comprising a positively- or negatively-valenced somatic state relating to the perceived risk or benefit (favourable or unfavourable), and that this directs the evaluation of the benefit or risk (high or low) and subsequent venturing behaviours (approach or avoid). The affect heuristic mediates between somatic state and opportunity evaluation (see Figure 1). Intuitive affect affords a decision maker an attribute that may or may not be appropriate in meeting goals but which enables low-effort heuristic processing; it is a default response that precedes any subsequent, high-effort, deliberative (System 2) processing intervention (see Evans \& Stanovich, 2013a). Hence:

Proposition 4a: Business venturing opportunities attended by a negative somatic state will be evaluated as high risk and low benefit;

Proposition 4b: Business venturing opportunities attended by a positive somatic state will be evaluated as low risk and high benefit. 


\section{System 2 Intervention and Validity of Decision Environment}

As noted above, Stanovich and West (2013a) identified important distinctions within dualprocess accounts in terms of whether System 1 (Type 1) and System 2 (Type 2) processing proceed in parallel ('parallel-competitive') "each having their say with conflict resolved if necessary" (p.227), or whether they proceed sequentially ('default-interventionist') whereby "fast Type 1 [System 1] processing generates intuitive default responses on which subsequent reflective Type 2 [System 2] processing may or may not intervene" (ibid.). Evans and Stanovich (2013a) argue that most decision making behaviour "will accord with defaults" (p.237) and declare default-interventionist to be the "preferred theoretical approach" (p.223) however "the exact nature of the interplay of the systems is debated" (Cokely et al. 2009: 2926).

In the model (Figure 1) intuition is a default process as occurring a result of the fast, automatic mobilisation of intuitive expertise, and augmented by a predisposition to process information intuitively (intuitive cognitive style). The intuitive recognition of a business opportunity is followed quickly by gut feel affective responses manifested as a somatic state that evokes feelings of rightness (favourable intuitive evaluation) or wrongness (unfavourable intuitive evaluation) and this serves as a heuristic that guides subsequent approach or avoid behaviours. The evocation of the affective response is spontaneous and rapid and precedes the intervention of System 2 processes. The decision makers' somatic state affords a positively- or negatively-valenced, easy-to-evaluate (though not necessarily accurate) attribute (Evans and Stanovich, 2013a) which guides decision making. In the model System 2 processes may or may not come into play in the evaluation of the business opportunity after the intuitively recognised opportunity has been somatically marked (by a 'gut feel' response) and its perceived risks and benefits evaluated affectively (by the operation of the affect heuristic). Hence: 
Proposition 5a: successful entrepreneurs spend more time rethinking intuitively recognized business opportunities.

Proposition 5b: successful entrepreneurs are more likely to change their evaluations of intuitively recognized business opportunities following System 2 interventions.

Strong, positively-valenced intuitions give rise to a level of confidence in the entrepreneur's initial intuitive assessment of the business venturing idea to the extent that he or she is less likely to spend time re-thinking or changing their answer irrespective of the relationship between confidence and accuracy (Evans \& Stanovich, 2013a; Thompson, Turner \& Pennycock, 2011). A rational/analytical cognitive style and/or higher cognitive ability may militate against such tendencies (Evans \& Stanovich, 2013) and therefore determine if System 2 intervention occurs. Time pressure and dynamism in the business environment (e.g. to achieve 'first mover' advantage in a market) are likely to militate against System 2 intervention.

The outcome of the above processes are entrepreneurs' business venturing decisions (e.g. whether to start-up a venture or not). This decision may lead to successful or unsuccessful exploitation of the intuitively perceived and evaluated business venturing opportunity. However, the accuracy and consequences of acting on intuitive judgements cannot be considered independently of the business environment in which such actions are taken. In mapping the boundary conditions that separate experts' intuitive judgments from overconfident and biased judgments Kahneman and Klein (2009) concluded two important points: first, whether or not an expert's intuitive judgment can be trusted depends on the opportunities that she or he has to learn the regularities and predictabilities of the environment in which he or she operates; second, decision-making contexts or environments have a high validity for intuitive judgment when there are stable relationships between objectively identifiable cues and events, or between cues and outcomes (e.g. the validities in 
medicine and fire-fighting are relatively high when compared to those of long-term political forecasting or predicting future values of individual stocks). Evans and Stanovich's (2013a) equivalent term for 'high versus low validity' environments is 'benign versus hostile'.

Business venturing environments vary in terms of their validity or benevolence and hence the extent to which they represent appropriate contexts in which intuitive judgment may be deployed legitimately and effectively. The effectiveness of intuitive judgement in the venturing context will likely be contingent on the validity (in the terms set out by Kahneman and Klein) or benevolence (in the terms set out by Stanovich and West) of the decision environment. For example, in certain new business domains (for example, e-commerce occupied a totally new business space in the so-called 'dot com bubble' into which many budding entrepreneurs ventured but not all succeeded) there is unlikely to be sufficient accumulated evidence for stable and predictable relationships between cues in the business environment and outcomes to support accurate intuitive judgment. Such an environment would have low validity and be hostile to the effective use of intuition. Business opportunities evaluated favourably on the basis of intuitive judgment are more likely to represent accurate assessments in high validity (benign) environments than low validity (hostile) environments. In low validity environments the success of intuitive judgments is more likely to be a function of chance and 'lucky hunches'. Hence:

Proposition 6: the accuracy of intuitive evaluations of business opportunities is positively related to the validity of the decision environment.

\section{DISCUSSION}

As well as proposing entrepreneurial intuition as a conceptually distinct and practically relevant type of intuition, this article also emphasizes the more general point that a dualprocessing framework provides a valuable theoretical resource for an improved 
understanding of the decision processes implicated in entrepreneurship because it can account for, accommodate, and acknowledge: (1) the default interventionist nature of non-conscious, implicit, and automatic processes in entrepreneurial decisions; (2) the significant role played by intuitive affect and somatic states in assessing risk and benefits in business venturing decisions; (3) individual differences in entrepreneurs' decision making behaviours; (4) the integrated and interdependent nature of intuitive cognition and intuitive affect in entrepreneurship. Moreover, dual-process conceptualizations in general offer greater parsimony and currency for the study of entrepreneurial cognition than previously-used theories (e.g. Gordon's 'proximity-to-consciousness' model, as cited in Mitchell et al., 2005) and are commensurable with emerging insights from cognitive neuroscience, social cognitive neuroscience, neurology, neuro-economics, and behavioural genetics (e.g. Bechara \& Damasio, 2005; Dijksterhuis \& Meurs, 2006; Lieberman, 2007; Nicolaou \& Shane, 2009; Nicolaou et al., 2008).

With regard to the application of dual-process theory to entrepreneurs' business venturing decisions it was noted that default-intervention is the preferred conceptualization of a number of dual-process theorists, and that this perspective was adopted in the model presented here (hence the name 'default-intervention model of entrepreneurial intuition'). One of the problems with the default-intervention model is that although the processes emanating from System 1 are acknowledged as being "rapid, preconscious, and computationally powerful" (Evans, 2007: 322) the nature of the defaults themselves are specified only in general terms, e.g. 'attribute substitution' (Evans \& Stanovich, 2013a: 237). A theoretical contribution of this article is that the nature of the System 1 defaults (see Figure 1) is specified for the entrepreneurial domain, namely: intuitive expertise (rapid, preconscious and computationally powerful); intuitive style (automatic default processing mode); somatic state and affect heuristic (attribute substitution). Whether these specific defaults are 
applicable and generalizable beyond the entrepreneurial domain is a theoretical and empirical question. A further contribution of model in so far as dual process theory is concerned is that it also specifies the point at and conditions under which System 2 interventions are likely to occur, e.g. availability of sufficient cognitive resources, reduced time pressure, etc.

An additional contribution stemming directly from this re-conceptualization in terms of System 1 defaults is a much-needed psychological explanation of the phenomenon of ‘entrepreneurial alertness'. Entrepreneurial alertness was first proposed by Kirzner (1979) and refers to the mental representations and interpretations which give entrepreneurs a unique 'insight' into the value of a given resource. It is a dimension of individual difference, possessed (or exercised) more by certain individuals, and enables them to perceive cues, for example market needs or under-employed resources, which others do not see (Kirzner, 2009; Manolova et al., 2002). Alertness may be the product of "genetic makeup, background and experience, and/or in the amount and type of information they possess about a particular opportunity" (Ardichvili, Cardozo \& Ray, 2003: 110). In terms of the model presented here alertness is part of the cognitive (intuitive expertise and style) and affective (sensitivity to somatic states) infrastructures necessary for entrepreneurs to be able to successfully recognize, evaluate, and act upon business venturing opportunities.

\section{Limitations}

Limitations of the model emanate from its baseline assumptions. In the 'defaultinterventionism' assumption Evans (2007) and Evans and Stanovich (2013a) assume that dual-process theories have to account for conflict between System 1 and System 2 processing, and propose three ways to resolve this question ('pre-emptive conflict resolution', 'default-intervention', and 'parallel-competitive'). Their preferred theoretical position, and that adopted here, is default-interventionism. The potential limitations stemming from this assumption are twofold: the first is the privileging of 'default-intervention' over 'parallel- 
competitive', however since the model presented here is concerned first and foremost with entrepreneurial intuition and intuitions are 'defaults' (i.e. rapid, spontaneous, heuristic) the former is a more viable starting point for theory building; the second is Evans' (2007) and Evans and Stanovich's (2013a) assumption that the two systems must necessarily conflict, hence the question arises 'need conflict be the case?' A higher-order assumption and concomitant limitation of the model presented here is the dual-process conceptualisation itself since, as has been noted, there are debates within cognitive and social psychology with regard to 'dual' (e.g. Epstein, 1994; Evans and Stanovich, 2013) versus 'uni' (e.g. Kruglanski, 2013) models of information processing. On balance the position taken in this article resonates with that of Evans and Stanovich (2013a: 237), namely "we do not support dual-processing approaches on the basis of whim and fashion. We do so because the evidence is compelling and because a very clear theoretical basis for the two-process distinction has now emerged". The default-intervention model of entrepreneurial intuition presented here affords work and organizational psychology researchers a framework within which these various assumptions can be tested.

\section{Future Research}

Taking the entrepreneurial intuition research agenda forward and testing the model's propositions requires a mix of approaches both qualitative and quantitative. The self-report assessment of entrepreneurs' cognitive styles (Proposition 2) requires the use of valid and reliable instruments that are compatible with dual-processing theories. Candidate instruments include: (1) Cognitive Style Index (CSI, Allinson \& Hayes, 1996) when scored in-line with the recommendations of Hodgkinson and Sadler-Smith (2003) (Coffield et al., 2004), and as implemented for example in Kickul, et al., (2009); (2) Preference for Intuition and Deliberation Scale (PID, Betsch, 2004), PID has weakly negatively correlated scales (approximating orthogonality), good reliabilities, and exists in English and Dutch translations 
as well as the original German but is untested in management research; (3) Vance, Groves, Paik, and Kindler's (2007) Linear-Nonlinear Thinking Style Profile (LNTSP) has been used in entrepreneurial cognition research (Groves, Vance, Choi \& Mendez, 2008) but does not measure intuition directly, rather intuition is inferred from 'nonlinear' thinking; (4) Rational Experiential Inventory (REI) is reliable, valid, predicated on Epstein's (1994) CognitiveExperiential Self-Theory (CEST), available in long- and short-forms, has been used by management intuition researchers (Chaston \& Sadler-Smith, 2012) but has only been validated extensively on a large-scale using samples of psychology majors (Epstein et al, 1996; Pacini \& Epstein, 1999).

As far as researching entrepreneurs' intuitive expertise is concerned, whether or not an entrepreneur possesses the complex domain relevant schemas (CDRSs) that typify an expert mind-set (Proposition 1) could be assessed by adopting and adapting the tacit knowledge tests developed by Wagner and Sternberg (1985). These scenario-based tests could be used alongside objective measures of entrepreneurial (e.g. 'one-off' versus serial) performance. CDRSs predispose an entrepreneur to potentially accurate intuitive decisions, but researchers might also examine the relationships between entrepreneurial intuition and failure, as well as success. The causes of success or otherwise of entrepreneurial intuitions and the role of System 2 processing (Proposition 5) could be analysed qualitatively using a variant of Flanagan's Critical Incident Technique (CIT) to examine intuitive entrepreneurial 'hits' and 'misses' (Akinci, 2014). Failure to scrutinize 'misses' may mean that intuitive 'hits' become lauded and contribute to the view of the omnipotence of high-profile intuitive entrepreneurs, whilst their 'misses' are ignored, overlooked or buried in the search for evidence of the 'powers' of intuition. Research might also be conducted across a variety of entrepreneurial business environments in order to explore the role played by environmental validity and benevolence (Proposition 6) in determining decision outcomes. 
The subjective experience of entrepreneurial intuition and the associated affective response (Proposition 3) is a potentially fruitful but under-researched line of inquiry. Further field studies are required in establishing the phenomenological nature of intuitive decisions in the entrepreneurial context in order to delineate "true intuition" from other forms of affective response and false attributions to intuition (Blume \& Covin, 2011: 137) and the ways in which intuition and analysis interact in vivo. Eliciting first-person accounts of intuitive episodes could draw on the Critical Incident Technique (see above) as well as methods of guided introspection based on psycho-phenomenology (Hodgkinson \& Sadler-Smith, 2011). A further intriguing question is how well-attuned 'intuitive entrepreneurs' are to their somatic state and whether such interoceptive awareness itself is an aspect of individual difference (see Dunn et al., 2010) that might help account for entrepreneurial successes and failures in business venturing

In terms of the neuroscience of entrepreneurial intuition laboratory studies using Iowa Gambling Task-type designs (Bechara \& Damasio, 2005) adapted to business venturing decisions might be used to explore the neurophysiological aspects of intuitive affective responses to potential business opportunities and subsequent decision-making processes (Propositions 3 and 4). The cognitive and affective changes that may occur during such business venturing tasks could be captured using fMRI and EEG measures and help to build a 'neural geography' (Segalowitz, 2007) of entrepreneurial intuition.. This type of research might also test entrepreneurs' responses to intuitive judgements in experimental designs that capture difference types of decision scenarios that are reflective of differences in the validity or benevolence of the decision environment (Proposition 6).

\section{Practical Implications}

In terms of practical implications of the model: first, intuition should be given greater recognition in the design of management training, entrepreneurship development and 
business education programs, and such programs should assist novice entrepreneurs in acquiring expert entrepreneurial prototypes, schemas and scripts and help them build intuitive expertise; second, individual differences in expertise and preferences for intuitive and analytical processing are relevant in the entrepreneurial process and therefore should be taken into account in the selection of teams for business venturing projects, new product development, or business start-ups; third, developing better understanding of intuitive judgment is important self-reflexively since knowing when/when not to discount intuitive signals has implications for how entrepreneurs can make optimal choices at crucial life junctures.

\section{Conclusion}

Theories of entrepreneurial decision making have tended to emphasize the role of analytic processes in guiding behaviour, however if viable psychological theory of the cognitive and affective processes implicated in the creation of successful entrepreneurial ventures is required then work psychology researchers need to better understand the role that intuition plays in the recognition and evaluation of business opportunities. The model presented in this article adds to the understanding of entrepreneurial intuition in two main ways: first it applies dual process theory, and more specifically the default-intervention model, to the entrepreneurial context; second, it offers psychological insights into the cognitive and affective processes operating in the recognition, evaluation and exploitation of business venturing opportunities. The potential benefits of conjoining work psychology and entrepreneurship research not only present a significant and much-needed contribution to knowledge by putting the 'person back into entrepreneurship', they also promise practical relevance and impact given the economic and social importance of business venturing decision making and entrepreneurial success. 


\section{REFERENCES}

Akinci, C. (2014) Capturing intuition in decision making: The case for the Critical Incident Technique. In M. Sinclair (Ed.) Handbook of Research Methods on Intuition. Cheltenham, UK: Edward Elgar.

Akinci, C., \& Sadler-Smith, E. (2012). Intuition in management research: A historical review. International Journal of Management Reviews, 14(1), 104-122.

Akinci, C., \& Sadler-Smith, E. (2013). Assessing individual differences in experiential (intuitive) and rational (analytical) cognitive styles. International Journal of Selection and Assessment, 21(2), 211-221.

Allinson, C.W., Chell E., \& Hayes, J. (2000). Intuition and entrepreneurial performance. European Journal of Work and Organizational Psychology 9(1), 31-43.

Allinson, CW., \& Hayes, J. (1996). The Cognitive Style Index: a measure of intuitionanalysis for organizational research. Journal of Management Studies 33, 119-135.

Ardichvili, A., Cardozo, R., \& Ray, S. (2003). A theory of entrepreneurial opportunity identification and development. Journal of Business Venturing, 18(1), 105-123.

Autio, E., George, G., \& Alexy, O. (2011). International entrepreneurship and capability development - qualitative evidence and future directions. Entrepreneurship Theory and Practice January: 11-37.

Baron, R.A. (2004). Potential benefits of the cognitive perspective: Expanding entrepreneurship's array of conceptual tools. Journal of Business Venturing 19, 169172.

Baron, R.A. (2006). Opportunity recognition as pattern recognition: How entrepreneurs 'connect the dots' to identify new business opportunities. Academy of Management Perspectives February: 104-119. 
Baron, R.A. (2008). The role of affect in the entrepreneurial process. Academy of Management Review, 33(2), 328-340.

Baron, R.A., \& Ensley, M.D. (2006). Opportunity recognition as the detection of meaningful patterns: evidence from comparisons of novice and experienced entrepreneurs. Management Science, 52(9): 1331-1344.

Baron, R.A., \& Ward, T.B. (2004). Expanding entrepreneurial cognition's toolbox: potential contributions from the field of cognitive science, Entrepreneurship Theory and Practice, 28(6), 553-518.

Barrow, C. (2009). Get backed, get big, get bought. Chichester: Capstone/Wiley

Bechara, A., \& Damasio, A.R. (2005). The somatic marker: A neural theory of economic decision, Games and Economic Behaviour, 52, 336-372.

Bechara, A., Damasio, A. R., Damasio, H., \& Anderson, S. W. (1994). Insensitivity to future consequences following damage to human prefrontal cortex. Cognition, 50(1), 715.

Bechara, A., Tranel, D., Damasio, H., \& Damasio, A. R. (1996). Failure to respond autonomically to anticipated future outcomes following damage to prefrontal cortex. Cerebral cortex, 6(2), 215-225.

Benner, P. \& Tanner, C. (1987) How expert nurses use intuition. American Journal of Nursing, January: 23-31.

Betsch, C. (2004) Preference for Intuition and Deliberation (PID): an inventory for assessing affect- and cognition-based decision-making. Zeitschrift für Differentielle und Diagnostiche Psychologie, 25, 179-197.

Betsch, C. (2008) Chronic preferences for intuition and deliberation in decision making: Lessons learned about intuition from an individual differences approach, In Plessner, 
H., Betsch, C. \& Betsch, T. (Eds.) Intuition in Judgement and Decision Making, 231248, New York: Lawrence Erlbaum Associates.

Bird, B. (1988). Implementing entrepreneurial ideas: the case for intention, Academy of Management Review, 13(3), 442-453.

Blume, B. \& Covin, J.G. (2011). Attributions to intuition in the venture founding process: Do entrepreneurs actually use intuition or just say they do? Journal of Business Venturing, 26, 137-151.

Branson, R. (2005). Losing My Virginity: The Autobiography. Revised Edition. London: Virgin Books.

Brigham, K.H., De Castro, J.O., Shepherd, D.A. (2007). A person-organization fit model of owner-managers' cognitive style and organizational demands. Entrepreneurship Theory and Practice January: 29-51.

Burke, L.A. \& Miller M.K. (1999). Taking the mystery out of intuitive decision making. Academy of Management Executive, 13(4), 91-99.

Busenitz, L. W., \& Barney, J. B. (1997). Differences between entrepreneurs and managers in large organizations: Biases and heuristics in strategic decision-making. Journal of Business Venturing, 12(1), 9-30.

Cardon, M. S., Foo, M. D., Shepherd, D., \& Wiklund, J. (2012). Exploring the heart: entrepreneurial emotion is a hot topic. Entrepreneurship Theory and Practice, 36(1), 110.

Chaston, I., \& Sadler-Smith, E. (2012). Entrepreneurial cognition, entrepreneurial orientation and firm capability in the creative industries. British Journal of Management, 23(3), 415-432. 
Coffield, F., Moseley, D., Hall, E., \& Ecclestone, K. (2004). Learning styles and pedagogy in post-16 learning: A systematic and critical review, London: Learning and Skills Research Centre.

Cokely, E.T., Parpart, P. \& Schooler, L.J. (2009). On the link between cognitive control and heuristic processes." In Proceedings of the $31^{\text {st }}$ Annual Conference of the Cognitive Science Society, 2926-2931.

Cools, E., Van den Broeck, H., \& Bouckenooghe, D. (2009). Cognitive styles and personenvironment fit: Investigating the consequences of cognitive (mis) fit. European Journal of Work and Organizational Psychology, 18(2), 167-198.

Craig, A.D. (2002). How do you feel? Interoception: the sense of the physiological condition of the body. Nature Reviews Neuroscience, 3(8), 355-366.

Cropley, A. (2006). In praise of divergent thinking. Creativity Research Journal, 18(3), 391-404.

Cross, B., \& Travaglione, A. (2003). The untold story: is the entrepreneur of the $21 \mathrm{st}$ century defined by emotional intelligence?. International Journal of Organizational Analysis, 11(3), 221-228.

Damasio, A.R. (2000). The feeling of what happens. New York: HarperCollins.

Dane, E., \& Pratt, M.G. (2007). Exploring intuition and its role in managerial decisionmaking. Academy of Management Review, 32(1), 33-54.

Dane, E. \& Pratt, M.G. (2009). Conceptualizing and measuring intuition: A review of recent trends. In G.P. Hodgkinson and J.K. Ford (Eds.), International Review of Industrial and Organizational Psychology - Volume 24: 1-40. Wiley: Chichester, UK 
De Carolis, D. M., Litzky, B. E., \& Eddleston, K. A. (2009). Why networks enhance the progress of new venture creation: The influence of social capital and cognition. Entrepreneurship Theory and Practice, 33(2), 527-545.

De Martino, B., Kumaran, D., Seymour, B., \& Dolan, R. J. (2006). Frames, biases, and rational decision-making in the human brain. Science, 313(5787), 684-687.

Dijksterhuis, A., \& Meurs, T. (2006). Where creativity resides: The generative power of unconscious thought. Consciousness and Cognition, 15, 135-146.

Dimov, D. (2007). Beyond the single-person, single-insight attribution in understanding entrepreneurial opportunities. Entrepreneurship Theory and Practice, 31(5), 713-731.

Dreyfus, H. L., \& Dreyfus, S. E. (2005). Peripheral vision expertise in real world contexts. Organization Studies, 26(5), 779-792.

Dunn, B. D., Galton, H.C. Morgan, R. Evans, D. Oliver, C. Meyer M. \& Dalgleish, T. (2010) Listening to your heart: How interoception shapes emotion experience and intuitive decision making. Psychological Science, 21(12), 1835-1844.

Eckhardt, J. T., \& Shane, S. A. (2003). Opportunities and entrepreneurship. Journal of Management, 29(3), 333-349.

Epstein, S. (1994). Integration of the cognitive and the psychodynamic unconscious. American Psychologist, 49, 709-724.

Epstein, S. (2010). Demystifying intuition: What it is, what it does, and how it does it. Psychological Inquiry, 21(4), 295-312.

Epstein, S., Pacini, R., Denes-Raj, V., \& Heier, H. (1996). Individual differences in intuitive-experiential and analytical-rational thinking styles. Journal of Personality and Social Psychology, 71, 390-405. 
Ericsson, K. A., Prietula, M. J., \& Cokely, E. T. (2007). The making of an expert. Harvard Business Review, 85(7/8), 114.

Ericsson, K. A., \& Ward, P. (2007). Capturing the naturally occurring superior performance of experts in the laboratory toward a science of expert and exceptional performance. Current Directions in Psychological Science, 16(6), 346-350.

Evans, J St.B.T. (2003). In two minds: dual process accounts of reasoning. Trends in Cognitive Sciences, 7(10), 454-459.

Evans, J. St. B. T. (2007). Hypothetical thinking: Dual processes in reasoning and judgement. Hove, England: Psychology Press.

Evans, J. St., B. T. (2008). Dual-processing accounts of reasoning, judgment, and social cognition. Annual Review of Psychology, 59, 255-278.

Evans, J. St. B. T. \& Stanovich K.E. (2013a) Dual-process theories of higher cognition advancing the debate. Perspectives on Psychological Science, 8(3), 223-241.

Evans, J. S. B., \& Stanovich, K. E. (2013). Theory and Metatheory in the Study of Dual Processing Reply to Comments. Perspectives on Psychological Science, 8(3), 263-271.

Finucane, M.L., Alhakami, A., Slovic, P., \& Johnson, S.M. (2000). The affect heuristic in judgment of risks and benefits. Journal of Behavioral Decision Making, 13, 1-17.

Foo, M-D., Uy, M.A., \& Baron, R.A. (2009). How do feelings influence effort? An empirical study of entrepreneur's affect and venture effort. Journal of Applied Psychology 94(4), 1086-1094.

Frese, M., Chell, E., \& Klandt, H. (2000). Introduction. European Journal of Work and Organizational Psychology, 9(1), 3-6.

Gore, J., \& Sadler-Smith, E. (2011). Unpacking intuition: A process and outcome framework. Review of General Psychology, 15(4), 304. 
Goss, D. (2005). Schumpeter's legacy? Interaction and emotions in the sociology of entrepreneurship. Entrepreneurship Theory and Practice, 29(2), 205-218.

Gregoire, D.A., Barr, P.S., \& Shepherd, D.A. (2010). Cognitive processes of opportunity recognition: The role of structural alignment. Organization Science, 21(2), 413-431.

Hammond, K.R., (1996), Human judgement and social policy. Oxford: Oxford University Press

Hodgkinson GP, \& Sadler-Smith E. (2011). Investigating intuition: Beyond self-report. In M. Sinclair (ed.) Handbook of Intuition Research. Chletenham: Edward Elgar: 52-66.

Hodgkinson, G.P., Sadler-Smith, E., Burke, L.A., Claxton, G. and Sparrow, P. (2009). Intuition in organizations: Some implications for strategic management. Long Range Planning, 42, 277-297.

Hodgkinson, G.P., Sadler-Smith, E., Sinclair, M. and Ashkanasy, N. (2009). More than meets the eye? Intuition and analysis revisited, Personality and Individual Differences, $47,342-346$.

Hogarth, R. M. (2001). Educating intuition. Chicago: University of Chicago Press.

Hogarth, R.M. (2010). Intuition: A challenge for psychological research on decision making. Psychological Inquiry, 21(4), 338-353.

Kahneman, D. (2011). Thinking, fast and slow. London: Penguin

Kahneman, D., \& Klein, G.A. (2009). Conditions for intuitive expertise: a failure to disagree. American Psychologist, 64(6), 515-526.

Keh, H. T., Foo, M. D., \& Lim, B. C. (2002). Opportunity evaluation under risky conditions: The cognitive processes of entrepreneurs. Entrepreneurship Theory and Practice, 27(2), 125-148.

Keren, G., \& Schul, Y. (2009). Two is not always better than one: A critical evaluation of two-system theories. Perspectives on Psychological Science, 4(6), 533-550. 
Kickul, J., Gundry, L.K., Barbosa, S.D., \& Whitcanack, L. (2009). Intuition versus analysis: Testing differential models of cognitive style in entrepreneurial self-efficacy and new venture creation process. Entrepreneurship Theory and Practice March: 439453.

Kirzner, I. (1979) Perception, opportunity and profit, Chicago: University of Chicago Press.

Kirzner, I. M. (2009). The alert and creative entrepreneur: a clarification. Small Business Economics, 32(2), 145-152.

Klein, G. (1998). Sources of power: how people make decisions. Cambridge, MA.: The MIT Press.

Kozhevnikov, M. (2007). Cognitive styles in the context of modern psychology: toward an integrated framework, Psychological Bulletin, 133(3), 464-481.

Krauss, S. I., Frese, M., Friedrich, C., \& Unger, J. M. (2005). Entrepreneurial orientation: A psychological model of success among southern African small business owners. European Journal of Work and Organizational Psychology, 14(3), 315-344.

Krueger, N.F. (2000). The cognitive infrastructure of opportunity emergence. Entrepreneurship Theory and Practice, Spring: 5-23.

Kruglanski, A. W. (2013) Only one? The default interventionist perspective as a unimodel—Commentary on Evans \& Stanovich (2013). Perspectives on Psychological Science, 8(3), 242-247.

Lewandowsky, S., Little, D. \& Kalish, M.L. (2007) Knowldeg and expertise. In Nickerson, R. S., Dumais, S. T., Lewandowsky, S., \& Perfect, T. J.. Handbook of Applied Cognition. F. T. Durso (Ed.). John Wiley \& Sons: 83-110.

Lieberman, M. D., Jarcho, J. M., \& Satpute, A. B. (2004). Evidence-based and intuitionbased self-knowledge: an FMRI study. Journal of Personality and Social Psychology, 87(4), 421. 
Lieberman, M.D. (2007). Social cognitive neuroscience: A review of core processes. Annual Review of Psychology, 58, 259-289.

Linton, J. D., \& Walsh, S. T. (2008). Acceleration and extension of opportunity recognition for nanotechnologies and other emerging technologies. International Small Business Journal, 26(1), 83-99.

Lyon, D. W., Lumpkin, G. T., \& Dess, G. G. (2000). Enhancing entrepreneurial orientation research: Operationalizing and measuring a key strategic decision making process. Journal of Management, 26(5), 1055-1085.

Manolova, T. S., Brush, C. G., Edelman, L. F., \& Greene, P. G. (2002). Internationalization of Small Firms Personal Factors Revisited. International Small Business Journal, 20(1), 931.

Mehta, M. (2013). The entrepreneurial instinct. New York: McGraw Hill Professional

Messick, S. (1984). The nature of cognitive styles: problems and promise in educational practice. Educational Psychologist, 19, 59-74.

Miller, A. (1987). Cognitive styles: An integrated model. Educational Psychology, 7(4), 251268.

Mitchell, J.R., Friga, P.N., \& Mitchell, R.K. (2005). Untangling the intuition mess: intuition as a construct in entrepreneurship research. Entrepreneurship Theory and Practice, November, 653-679.

Mitchell, R. K. (2005). Tuning up the global value creation engine: The road to excellence in international entrepreneurship education. In D.A. Shepherd and J.A. Katz (Eds.) Advances in entrepreneurship, firm emergence and growth, 8, 185-248, Amsterdam: Elsevier.

Mitchell, R.K., Busenitz, L., Lant, T., McDougall, P.P., Morse, E., \& Brock Smith, J. (2004). The distinctive and inclusive domain of entrepreneurial cognition research. Entrepreneurship Theory and Practice Winter, 505-518. 
Mitchell, R.K., Busenitz, L., Lant, T., McDougall, P.P., Morse, E., \& Brock Smith, J. (2002). Toward a theory of entrepreneurial cognition: Rethinking the people side of entrepreneurship research. Entrepreneurship Theory and Practice Winter, 93-104.

Nicolaou, N., \& Shane, S. (2009). Can genetic factors influence the likelihood of engaging in entrepreneurial activity? Journal of Business Venturing, 24, 1-22.

Nicolaou, N., Shane, S., Cherkas, L., \& Spector, T.D. (2008). The influence of sensation seeking in the heritability of entrepreneurship. Strategic Entrepreneurship Journal, 2, 721.

Osman, M. (2004). An evaluation of dual-process theories of reasoning. Psychonomic Bulletin \& Review, 11, 988-1010.

Pacini, R. \& Epstein S. (1999) The relation of rational and experiential information processing styles to personality, basic beliefs, and the ratio-bias phenomenon. Journal of Personality and Social Psychology, 76, 972-987.

Raidl, M.-H., \& Lubart, T.I. (2001). An empirical study of intuition and creativity. Imagination, Cognition and Personality, 20, 217-230.

Rauch, A., \& Frese, M. (2007). Let's put the person back into entrepreneurship research: A meta-analysis on the relationship between business owners' personality traits, business creation, and success. European Journal of Work and Organizational Psychology,16(4), $353-385$.

Read, S., Dew, N., Sarasvathy, S. D., Song, M., \& Wiltbank, R. (2009). Marketing under uncertainty: The logic of an effectual approach. Journal of Marketing, 73(3), 1-18.

Reber, A.S. (1993). Implicit learning and tacit knowledge: An essay on the cognitive unconscious. Oxford: Oxford University Press. 
Reimann, M., \& Bechara, A. (2010). The somatic marker framework as a neurological theory of decision-making: Review, conceptual comparisons, and future neuro-economics research. Journal of Economic Psychology, 31(5), 767-776.

Runco, M. A. (1991). Divergent thinking. Stamford: Ablex Publishing.

Sadler-Smith, E., \& Shefy, E. (2004). The intuitive executive: understanding and applying "gut feel" in decision-making. The Academy of Management Executive 18(4), 76-92.

Salas, E., Rosen, M.A., \& DiazGranados, D. (2010). Expertise-based intuition and decision making in organizations. Journal of Management, 36, 941-973.

Schenkel, M. T., Matthews, C. H., \& Ford, M. W. (2009). Making rational use of 'irrationality'? Exploring the role of need for cognitive closure in nascent entrepreneurial activity. Entrepreneurship and Regional Development, 21(1), 51-76.

Schneider, W., \& Shiffrin, R. M. (1977). Controlled and automatic human information processing: I. Detection, search, and attention. Psychological Review, 84(1), 1.

Segalowitz, S. J. (2007). Knowing before we know: Conscious versus preconscious topdown processing and a neuroscience of intuition. Brain and Cognition, 65(2), 143-144.

Shane, S., \& Venkataraman, S. (2000). The promise of entrepreneurship as a field of research. Academy of Management Review 25(1), 217-226.

Shiffrin, R. M., \& Schneider, W. (1977). Controlled and automatic human information processing: II. Perceptual learning, automatic attending and a general theory. Psychological Review, 84(2), 127.

Simon, H.A. (1987). Making management decisions: The role of intuition and emotion. Academy of Management Executive, 1(1), 57-64.

Simonton, D.K. (1980). Intuition and analysis: a predictive and explanatory model. Genetic Psychology Monographs, 102, 3-60.

Sinclair, M. (2010). Misconceptions about intuition. Psychological Inquiry, 21(4), 378-386. 
Sloman, S.A. (1996). The Empirical Case for Two Systems of Reasoning. Psychological Bulletin, 119(1), 3-22.

Slovic, P., Finucane, M., Peters, E., \& MacGregor, D. G. (2002). Rational actors or rational fools: Implications of the affect heuristic for behavioral economics. The Journal of SocioEconomics, 31(4), 329-342.

Slovic, P., Finucane, M.L., Peters, E., \& MacGregor, D.G. (2004). Risk as analysis and risk as feelings: Some thoughts about affect, reason, risk, and rationality, Risk Analysis, 24(2), 311-322.

Smith, E. R., \& DeCoster, J. (2000). Dual-process models in social and cognitive psychology: Conceptual integration and links to underlying memory systems. Personality and Social Psychology Review, 4(2), 108-131.

Smith, J. B., Mitchell, J. R., \& Mitchell, R. K. (2009). Entrepreneurial scripts and the new transaction commitment mindset: Extending the expert information processing theory approach to entrepreneurial cognition research. Entrepreneurship Theory and Practice, $33(4), 815-844$.

Stanovich, K.E., \& West, R.F. (2000). Individual differences in reasoning: implications for the rationality debate? Behavioral and Brain Sciences, 23, 645-65.

Sternberg, R.J. (2006). The nature of creativity. Creativity Research Journal 18(1) 87-98.

Tang, J., Kacmar, K. M., \& Busenitz, L. (2012). Entrepreneurial alertness in the pursuit of new opportunities. Journal of Business Venturing, 27(1), 77-94.

Thompson, V. A. (2009). Dual-process theories: A metacognitive perspective. In J. St. B. T. Evans \& K. Frankish (Eds.), In two minds: Dual processes and beyond (pp. 171-196). Oxford, England: Oxford University Press.

Thompson, V. A., Turner, J. P., \& Pennycock, G. (2011). Intuition, reason and metacognition. Cognitive Psychology, 63, 107-140. 
Utsch, A., \& Rauch, A. (2000). Innovativeness and initiative as mediators between achievement orientation and venture performance. European Journal of Work and Organizational Psychology, 9(1), 45-62.

Vaghely, I. P., \& Julien, P. A. (2010). Are opportunities recognized or constructed?: An information perspective on entrepreneurial opportunity identification. Journal of Business Venturing, 25(1), 73-86.

Vance, CM., Groves, KS., Paik, Y.\& Kindler, H. (2007). Understanding and measuring linear-nonlinear thinking style for enhanced management education and professional practice, Academy of Management Learning and Education, 6(2): 167-185.

Wagner, R.K., \& Sternberg, R.J. (1985). Practical intelligence in real-world pursuits: The role of tacit knowledge, Journal of Personality and Social Psychology, 48, 436-458.

Welch, J., \& Byrne, J.A. (2001). Jack: Straight from the gut. New York: Warner Books.

Zahra, S. A., Korri, J. S., \& Yu, J. (2005). Cognition and international entrepreneurship: implications for research on international opportunity recognition and exploitation. International Business Review, 14(2), 129-146. 


\section{Figure 1.}

Default-intervention model of entrepreneurial intuition

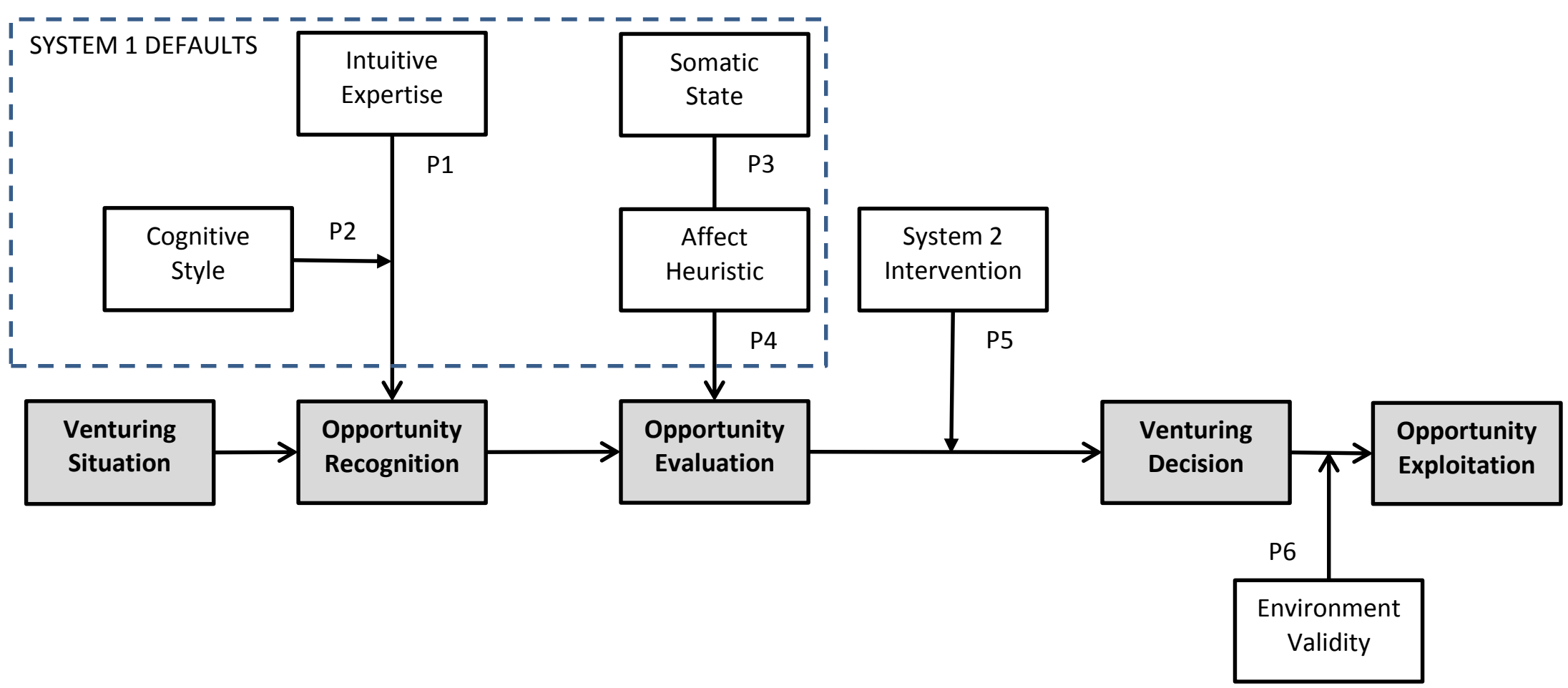


Table 1.

Typical clusters of attributes associated with System 1 and System 2

\begin{tabular}{lll}
\hline Source & System 1 ('Intuitive') & System 2 ('Analytical') \\
\hline Epstein & Holistic; Automatic, Effortless; & Analytic; Intentional; Effortful; \\
(1994) & Affective; Associationistic & Rational; Logical connections; \\
& connections; Behaviour mediated by & Behaviour mediated by conscious \\
& 'vibes'; Encodes in concrete images, & appraisal; Encodes in abstract \\
& metaphors, narratives; Rapid & symbols, words, numbers; Slower \\
& processing; More resistant to & processing; Less resistant to change \\
& change & \\
Lieberman & Parallel processing; Faster & Serial processing; Slower operating; \\
(2007) & operating; Slower learning; Non- & Fast learning; Reflective \\
& reflective consciousness; & consciousness; Intentional; \\
& Spontaneous; Sensory; Unaffected & Linguistic; Affected by cognitive \\
& by cognitive load; Phylogenetically & load; Phylogenetically newer \\
& older & \\
\hline Stanovich & 'Old mind' (System 1): evolved early; & 'New mind' (System 2): evolved \\
(2013a) & similar to animal cognition; implicit & late; distinctively human; explicit \\
& knowledge; basic emotions & knowledge; complex emotions \\
\hline Evans \& & &
\end{tabular}

